\title{
2-Year Natural Decline of Cardiac Sympathetic Innervation in Idiopathic Parkinson Disease Studied with ${ }^{11}$ C-Hydroxyephedrine PET
}

\author{
Ka Kit Wong ${ }^{1,2}$, David M. Raffel ${ }^{1}$, Nicolaas I. Bohnen ${ }^{1-4}$, Gulcin Altinok ${ }^{1}$, Sid Gilman ${ }^{5}$, and Kirk A. Frey , $^{1,6}$ \\ ${ }^{I}$ Division of Nuclear Medicine, Department of Radiology, University of Michigan, Ann Arbor, Michigan; ${ }^{2}$ VA Ann Arbor Healthcare \\ System, GRECC, Ann Arbor, Michigan; ${ }^{3}$ Functional Neuroimaging, Cognitive and Mobility Laboratory, Departments of Radiology \\ and Neurology, University of Michigan, Ann Arbor, Michigan; ${ }^{4}$ University of Michigan Morris K. Udall Center of Excellence for \\ Parkinson's Disease Research, Ann Arbor, Michigan; ${ }^{5}$ Department of Neurology, University of Michigan (retired), Ann Arbor, \\ Michigan; and ${ }^{6}$ Department of Neurology, University of Michigan, Ann Arbor, Michigan
}

The objective of this study was to detect regional patterns of cardiac sympathetic denervation in idiopathic Parkinson disease (IPD) using ${ }^{11} \mathrm{C}$-hydroxyephedrine $\left({ }^{11} \mathrm{C}-\mathrm{HED}\right) \mathrm{PET}$ and determine the denervation rate over $2 \mathrm{y}$. Methods: We obtained 62 cardiac ${ }^{11} \mathrm{C}-\mathrm{HED}$ PET scans in 39 patients (30 men and 9 women; mean age $\pm \mathrm{SD}, 61.9 \pm 5.9 \mathrm{y}$ ), including 23 patients with follow-up scans at $2 \mathrm{y}$. We derived ${ }^{11} \mathrm{C}-\mathrm{HED}$ retention indices (Rls; $\mathrm{mL}$ of blood/ $\mathrm{min} / \mathrm{mL}$ of tissue) reflecting nerve density and integrity for 480 left ventricular (LV) sectors. We compared IPD patients with 33 healthy controls using $z$ score analysis; $\mathrm{RI}$ values $\leq 2.5 \mathrm{SDs}$ were considered abnormal. We expressed global and regional LV denervation as the percentage extent of $z$ score severity and severityextent product (SEP) on 9-segment bullseye maps and decline in cardiac sympathetic innervation as the 2-y difference in SEP (diff-SEP). Results: Baseline ${ }^{11} \mathrm{C}-\mathrm{HED}$ PET in the 39 IPD patients revealed an $\mathrm{Rl}$ mean of $0.052 \pm 0.022 \mathrm{~mL}$ of $\mathrm{blood} / \mathrm{min} / \mathrm{mL}$ of tissue. In comparison with data from normal controls, 12 patients had normal ${ }^{11} \mathrm{C}$-HED PET, 5 showed mild denervation (percentage extent $<30 \%$ ), and 22 had moderate to severe denervation (percentage extent $>30 \%, z$ score $\leq 2.5 \mathrm{SD}$ ). In the 23 paired PET scans, worsening cardiac denervation (global diff-SEP $>$ 9) occurred in 14 of $23(60.9 \%)$ patients over $2 \mathrm{y}$, including percentage LV abnormality (59\% increasing to $66 \%$ ), z-severity (-2.4 down to $-2.5)$, and SEP (-195 to -227$)(P=0.0062)$. We found a mean annual decline of $4.6 \% \pm 5.6$ (maximum, $13 \%$ ) in ${ }^{11} \mathrm{C}$-HED retention from a baseline global RI mean of $0.0481 \pm 0.0218$ to $0.0432 \pm$ $0.0220(P=0.0009)$. At baseline, 5 patients with normal uptake had no interval change; 3 with mild denervation developed interval decline in lateral and inferior segments (diff-SEP -82 to -99) compared with anterior and septal segments (-65 to -79$)$, whereas the reverse pattern occurred in 15 patients with severe baseline denervation. Conclusion: Progressive decline in cardiac sympathetic neural integrity in IPD patients occurs at a modest rate over 2 y on ${ }^{11} \mathrm{C}-\mathrm{HED}$ scans with marked heterogeneity and a regional pattern of involvement and decline.

Received Apr. 15, 2016; revision accepted Jul. 21, 2016.

For correspondence or reprints contact: Ka Kit Wong, Department of Nuclear Medicine/Radiology, University of Michigan, 1500 E. Medical Center Dr., B1G505 UH, Ann Arbor, MI, 48109-0028.

E-mail: kakit@med.umich.edu

Published online Aug. 18, 2016.

COPYRIGHT (C) 2017 by the Society of Nuclear Medicine and Molecular Imaging.
Key Words: autonomic nervous system; cardiac sympathetic denervation; Parkinson disease; ${ }^{11} \mathrm{C}$-hydroxyephedrine PET

J Nucl Med 2017; 58:326-331

DOI: 10.2967/jnumed.116.176891

diopathic Parkinson disease (IPD) is an $\alpha$-synucleinopathy characterized in part by loss of dopaminergic neurons in the substantia nigra pars compacta (1). Beyond this, IPD is a progressive multisystem disease with motor and nonmotor dysfunction due to cerebral and extracerebral Lewy body accumulation, including postganglionic, presynaptic neurons and distal axons of the autonomic nervous system (2). Extensive cardiac sympathetic neuronal loss has been demonstrated on ${ }^{123}$ I-metaiodobenzylguanidine ( $\left.{ }^{123} \mathrm{I}-\mathrm{MIBG}\right)$ imaging $(3-8),{ }^{11} \mathrm{C}$-meta-hydroxyephedrine $\left({ }^{11} \mathrm{C}-\mathrm{HED}\right)$ (9-11), and ${ }^{18}$ F-fluorodopamine $\left({ }^{18} \mathrm{~F}-\mathrm{DA}\right)$ PET $(12,13)$, occurring early in the course of disease before development of the classic symptoms of tremor, rigidity, bradykinesia, and postural instability (14-16).

Losses in cardiac uptake and retention of ${ }^{123}$ I-MIBG, a false analog of norephinephrine, have been proposed as a diagnostic tool for detection of the prodromal phase of IPD $(14,16) .{ }^{11} \mathrm{C}$-HED PET provides similar assessment of cardiac sympathetic neural integrity with the advantages of higher spatial resolution, attenuation correction, and 3-dimensional tomographic regional evaluation of the myocardium (17-19). Both ${ }^{123}$ I-MIBG scintigraphy and ${ }^{11} \mathrm{C}-\mathrm{HED}$ PET may be able to distinguish IPD from other parkinsonian disorders such as multiple system atrophy, although neurodegeneration of preganglionic central nervous system glia can cause abnormal ${ }^{123}$ I-MIBG scintigraphy and ${ }^{11} \mathrm{C}-\mathrm{HED}$ PET findings $(9,10)$.

Despite considerable accumulated literature, we still have little information about the natural history of cardiac sympathetic denervation in IPD. We hypothesized heterogeneous patterns and nonuniform rates of progression in ${ }^{11} \mathrm{C}-\mathrm{HED}$ abnormalities and sought to quantify the rate of decline in sympathetic neural integrity over $2 \mathrm{y}$.

\section{MATERIALS AND METHODS}

The Institutional Review Board of the University of Michigan approved this study, and we obtained written informed consent from 
all patients and healthy controls. This study was compliant with the Health Insurance Portability and Accountability Act (clinicaltrials. gov identifier NCT01565473). This study was not funded by industrial or commercial sources nor did it evaluate products for commercial purposes.

We established the diagnosis of IPD using published research criteria (20), clinical neurologic examination, and the results of a $(+)-{ }^{11} \mathrm{C}$-dihydrotetrabenazine $\left({ }^{11} \mathrm{C}\right.$-DTBZ) vesicular monoamine transporter type 2 PET scan. PET neuroimaging experts reviewed all ${ }^{11} \mathrm{C}$-DTBZ scans at monthly consensus meetings and confirmed them to be consistent with IPD based on finding of nigrostriatal dopaminergic denervation. Details of the ${ }^{11} \mathrm{C}$-DTBZ PET protocol have been published previously $(11,21)$.

We screened patients with IPD and control subjects to exclude those with a history of cardiac disease, congestive cardiac failure, or diabetes mellitus and those with Q-waves or ST-segment changes on electrocardiography.

We obtained 62 cardiac ${ }^{11} \mathrm{C}$-HED PET scans in 39 patients (30 men and 9 women; mean age $\pm \mathrm{SD}, 61.9 \pm 5.9 \mathrm{y}$; age range, 50-73 y) including 23 patients with follow-up ${ }^{11} \mathrm{C}$-HED PET at 2 -y duration (mean $\pm \mathrm{SD}, 2.2 \pm 0.18 \mathrm{y}$ ). Mean levodopa equivalent dose in the patients was $570.4 \pm 335.9 \mathrm{mg}$. This cohort represents part of an earlier published report of IPD patients studied with ${ }^{11} \mathrm{C}$-HED PET (11), now reported in a larger group with analysis of follow-up scan data. The protocol for cardiac ${ }^{11} \mathrm{C}$-HED PET scanning and segmental analysis has been previously published and is briefly summarized here (11).

We obtained 40-min dynamic cardiac PET scans with an ECAT Exact HR + PET scanner (Siemens Medical Solutions) after intravenous injection of a mean of $740 \mathrm{MBq}$ of ${ }^{11} \mathrm{C}-\mathrm{HED}$. Attenuation correction was performed using $3{ }^{68} \mathrm{Ge}$ line sources. A region of interest placed over the left ventricular (LV) chamber near the base of the heart was used to generate a time-activity curves for total activity in blood. The LV wall was subdivided into each of the 8 short-axis sections from apex to base into 60 angular sectors, thereby generating 480 sectors. As a semiquantitative measure of nerve density and neuronal integrity, we normalized tissue ${ }^{11} \mathrm{C}-\mathrm{HED}$ concentrations in the final image frame (30-40 min after injection) by dividing them by the integral of the blood time-activity curve over the 40 -min scan. This procedure provided a ${ }^{11} \mathrm{C}$-HED retention index (RI, in $\mathrm{mL}$ of blood $/ \mathrm{min} / \mathrm{mL}$ of tissue) for each myocardial region. We used the RIs of 33 healthy control subjects (15 men and 18 women aged 20-78 y; mean age, 47 y) to define a normal ${ }^{11} \mathrm{C}$-HED retention database. We compared RI data of each IPD patient with the healthy control database by means of $z$ score analysis, with $z$ scores of less than 2.5 considered to be abnormal ${ }^{11} \mathrm{C}$-HED retention. We applied an age-adjustment factor to the ${ }^{11} \mathrm{C}$-HED RI values of the patients with IPD, normalizing to an age of $50 \mathrm{y}$. The control group had a modest decline of the ${ }^{11} \mathrm{C}$-HED RI with age $(1.3 \%$ decline per decade).

We expressed global, regional, and segmental measurements of abnormal cardiac sympathetic denervation as percentage extent, $z$ score severity, and severity-extent product (SEP). We obtained the SEP by multiplying the percentage extent and the $z$ score severity integers, combining percentage extent and severity of sympathetic denervation into a single product. We assessed the interval progression between serial ${ }^{11} \mathrm{C}$-HED PET scans by the difference of the SEP scores (diff-SEP). We performed visual assessment of regional cardiac sympathetic innervation with bullseye and polar maps.

We performed statistical analysis using SAS and STATA software (version 9.1 [SAS Institute] and version 11.1 [StataCorp], respectively). We compared serial ${ }^{11} \mathrm{C}$-HED PET cardiac parameters using the Wilcoxon signed-rank test and sign test. We also compared 2 sub- groups of IPD patients, those with normal findings or mild cardiac sympathetic denervation and those with severe cardiac sympathetic denervation using the Student $t$ test.

\section{RESULTS}

\section{Baseline Studies}

In the 39 patients with IPD, mean disease duration was $4.7 \pm$ $3.2 \mathrm{y}$ (range, 1-14 y) and mean Hoehn and Yahr score was $2.2 \pm$ 0.4 (range, 1-2.5). Baseline ${ }^{11} \mathrm{C}-\mathrm{HED}$ PET in these patients had an age-adjusted global RI mean of $0.052 \pm 0.022 \mathrm{~mL}$ of blood $/ \mathrm{min} / \mathrm{mL}$ of tissue. In comparison, the 33 control subjects had an age-adjusted mean ${ }^{11} \mathrm{C}-\mathrm{HED}$ RI of $0.086 \pm 0.015 \mathrm{~mL}$ of blood $/ \mathrm{min} / \mathrm{mL}$ of tissue. There was no significant correlation between the levodopaequivalent dose and the age-adjusted global RI in the PD patients ( $\mathrm{R}=-0.13$, not significant). The individual $\mathrm{RI}$ measurements and global and regional LV parameters are presented in Supplemental Table 1 (supplemental materials are available at http://jnm.snmjournals.org).

The IPD patients showed a binomial distribution of denervation: 12 had normal ${ }^{11} \mathrm{C}-\mathrm{HED}$ PET scan results and 5 had mild denervation (percentage extent $<30 \%)$ whereas the remaining $(22 / 39$, $56.4 \%$ ) had moderate to severe denervation (percentage extent $>30 \%, z$ score $\leq 2.5 \mathrm{SD}$ ). The mean percentage LV extent denervation was $50 \%$ (range, $0-100$ ), the mean $z$ score severity was -2.2 (range, -3.6 to 0.28 ), and the mean SEP was $-162 \pm 142$ (range, -358 to 0 ). We observed a regional pattern of severe and frequent involvement of the lateral and inferior cardiac territories (Supplemental Figs. 1A and 2). Patients with normal or mild denervation did not differ significantly from those with severe denervation with respect to age, duration of motor disease, Hoehn and Yahr stage, motor Unified Parkinson Disease Rating Scale scores, or vesicular monoamine transporter type 2 imaging striatal findings with ${ }^{11}$ C-DTBZ PET (Table 1).

\section{2-Year Follow-up Studies}

In the 23 patients with follow-up ${ }^{11} \mathrm{C}$-HED PET imaging, the frequency distribution of cardiac sympathetic denervation also followed a binomial distribution (Supplemental Fig. 1B). These 23 paired PET scans demonstrated worsening cardiac denervation over 2 y in 14 of $23(60.9 \%)$ patients, percentage LV abnormality $(59 \%$ increasing to $66 \%), z$ score severity $(-2.4$ down to -2.5$)$, and SEP $(-195$ down to -227$)(P=0.0062)$. There was a mean annual decline of $4.6 \% \pm 5.6 \%(\max , 13 \%)$ in ${ }^{11} \mathrm{C}$-HED uptake and retention from baseline age-adjusted global RI mean of $0.0481 \mathrm{~mL} \pm 0.0218 \mathrm{~mL}$ of blood $/ \mathrm{min} / \mathrm{mL}$ of tissue to $0.0432 \pm 0.0220(P=0.0009)$ (Table 2; Fig. 1$)$.

Segmental analysis of diff-SEP revealed an overall uniform global reduction in cardiac sympathetic innervation over $2 \mathrm{y}$. When analyzed by baseline ${ }^{11} \mathrm{C}$-HED PET classification, the data revealed segmental patterns of decline: 5 patients with normal scans at baseline showed no significant interval change; 3 patients with mild denervation (percentage extent $<30 \%$ ) showed preferential decline in distal lateral, inferior, and apical segments (diffSEP range between -82 and -99) compared with anterior and septal segments ( -65 to -79 ); and 15 patients with severely abnormal baseline scans showed further progression preferentially involving the anterior and septal segments (diff-SEP range, -39 to $-65)$ and less so the lateral, inferior, and apical segments ( -25 to -40) (Fig. 2). Polar plots of cardiac denervation patterns are presented in Figures 3 and 4. 
TABLE 1

Group Comparison Results of Clinical Variables and ${ }^{11} \mathrm{C}-\mathrm{DTBZ}$ PET Variables in Group of Patients $(n=17)$ with Either Normal or Partial, Mild Cardiac Denervation (Global SEP $\geq 100)$ Versus Group of Patients $(n=22)$ with More Extensive Cardiac Denervation (Global SEP $\leq 150$ )

\begin{tabular}{|c|c|c|c|}
\hline Variable & $\begin{array}{c}\text { Normal or relatively preserved sympathic } \\
\text { cardiac innervation }(n=17)\end{array}$ & $\begin{array}{c}\text { More extensive sympathetic cardiac } \\
\text { denervation }(n=22)\end{array}$ & Student $t$ test \\
\hline Age & $63.7 \pm 5.8$ & $61.0 \pm 5.9$ & $1.3994(P=0.0850)$ \\
\hline MoCa score & $25.63 \pm 1.69$ & $26.84 \pm 1.92$ & $1.55(P=0.14)$ \\
\hline $\begin{array}{l}\text { Duration of motor } \\
\text { disease }(y)\end{array}$ & $4.3 \pm 3.2$ & $5.1 \pm 3.1$ & $-0.8347(P=0.2046)$ \\
\hline Hoehn and Yahr stage & $2.23 \pm 0.32$ & $2.18 \pm 0.42$ & $0.3776(P=0.3541)$ \\
\hline $\begin{array}{l}\text { Nonmotor experiences } \\
\text { of daily living }\end{array}$ & $5.24 \pm 4.42$ & $6.54 \pm 5.51$ & $-0.8005(P=0.7857)$ \\
\hline \multicolumn{4}{|l|}{ UPDRS scores } \\
\hline Motor UPDRS scores & $27.74 \pm 7.30$ & $28.86 \pm 13.412$ & $-0.3122(P=0.6217)$ \\
\hline $\begin{array}{l}\text { UPDRS tremor } \\
\text { scores }\end{array}$ & $4.13 \pm 43.10$ & $3.39 \pm 2.71$ & $0.7410(P=0.2321)$ \\
\hline UPDRS PIGD scores & $5.43 \pm 3.06$ & $6.08 \pm 3.21$ & $-0.5943(P=0.7218)$ \\
\hline Fatigue severity scale & $22.75 \pm 12.86$ & $32.16 \pm 13.18$ & $1.71(P=0.10)$ \\
\hline $\begin{array}{l}\text { Epworth sleepiness } \\
\quad \text { scale }\end{array}$ & $6.35 \pm 2.78$ & $8.29 \pm 4.27$ & $-1.6088(P=0.0582)$ \\
\hline Striatal ${ }^{11} \mathrm{C}$-DTBZ DVR & $2.04 \pm 0.27$ & $1.91 \pm 0.30$ & $1.3043(P=0.1002)$ \\
\hline $\begin{array}{l}\text { Putamen }{ }^{11} \mathrm{C}-\mathrm{DTBZ} \\
\text { DVR }\end{array}$ & $1.90 \pm 0.25$ & $1.78 \pm 0.30$ & $1.3764(P=0.0886)$ \\
\hline $\begin{array}{l}\text { Caudate nucleus }{ }^{11} \mathrm{C}- \\
\text { DTBZ DVR }\end{array}$ & $2.00 \pm 0.33$ & $1.88 \pm 0.33$ & $1.0882(P=0.1419)$ \\
\hline
\end{tabular}

$\mathrm{MoCa}=$ Montreal Cognitive Assessment; UPDRS = Unified Parkinson Disease Rating Scale; PIGD = postural instability and gait difficulties; DVR = distribution volume ratio.

Data in parentheses are significance levels.

\section{DISCUSSION}

Our findings indicate significant heterogeneity of cardiac sympathetic denervation in IPD. Just over half of the patients showed extensive denervation with a regional pattern of sympathetic neuronal loss, preferentially involving the inferior and lateral LV walls, and relatively sparing the anterior and septal walls, confirming our earlier observations (11). This regional pattern of involvement was found also with ${ }^{18} \mathrm{~F}$-fluorodopamine PET imaging, with relatively lower sympathetic innervation in the lateral wall, with sparing of the septum $(22,23)$.

Progressive decline in cardiac sympathetic neural integrity occurs at a modest rate, as we observed with ${ }^{11} \mathrm{C}-\mathrm{HED}$ PET scans at a 2-y interval. This is similar to findings on serial ${ }^{18} \mathrm{~F}$-fluorodopamine PET imaging; radioactivity on the second study was decreased by $31 \%$ in the LV free wall compared with only $16 \%$ in the septum, with a mean interval of $2 \mathrm{y}$ between studies $(12,22)$. We found, however, that serial ${ }^{11} \mathrm{C}$-HED PET scans showed

TABLE 2

Baseline and 2-Year Follow-up ${ }^{11}$ C-HED PET Left Ventricle Sympathetic Cardiac Denervation in 23 Patients with IPD

\begin{tabular}{lccc}
\hline \multicolumn{1}{c}{ Variable } & Baseline & 2-y follow-up & Matched-paired Student $t$ test \\
\hline Global LV (mL of blood/min/mL of tissue) & $0.0481 \pm 0.0218$ & $0.0432 \pm 0.0220$ & $3.509(P=0.001)$ \\
\hline Percentage LV extent (\%) & 59.2 & 66.1 & $-2.198(P=0.0194)$ \\
Z-severity LV & -2.44 & -2.52 & $0.8007(P=$ not significant) \\
Percentage left circumflex extent (\%) & 66.0 & 69.6 & $-2.2218(P=0.0184)$ \\
Percentage left anterior descending extent (\%) & 56.2 & 65.0 & $-2.3940(P=0.0128)$ \\
Percentage right coronary artery extent (\%) & 61.7 & 65.7 & $-1.3490(P=0.0955$, not significant) \\
Global LV SEP & -194.6 & -226.6 & $2.944(P=0.003)$
\end{tabular}

Data in parentheses are significance levels. 


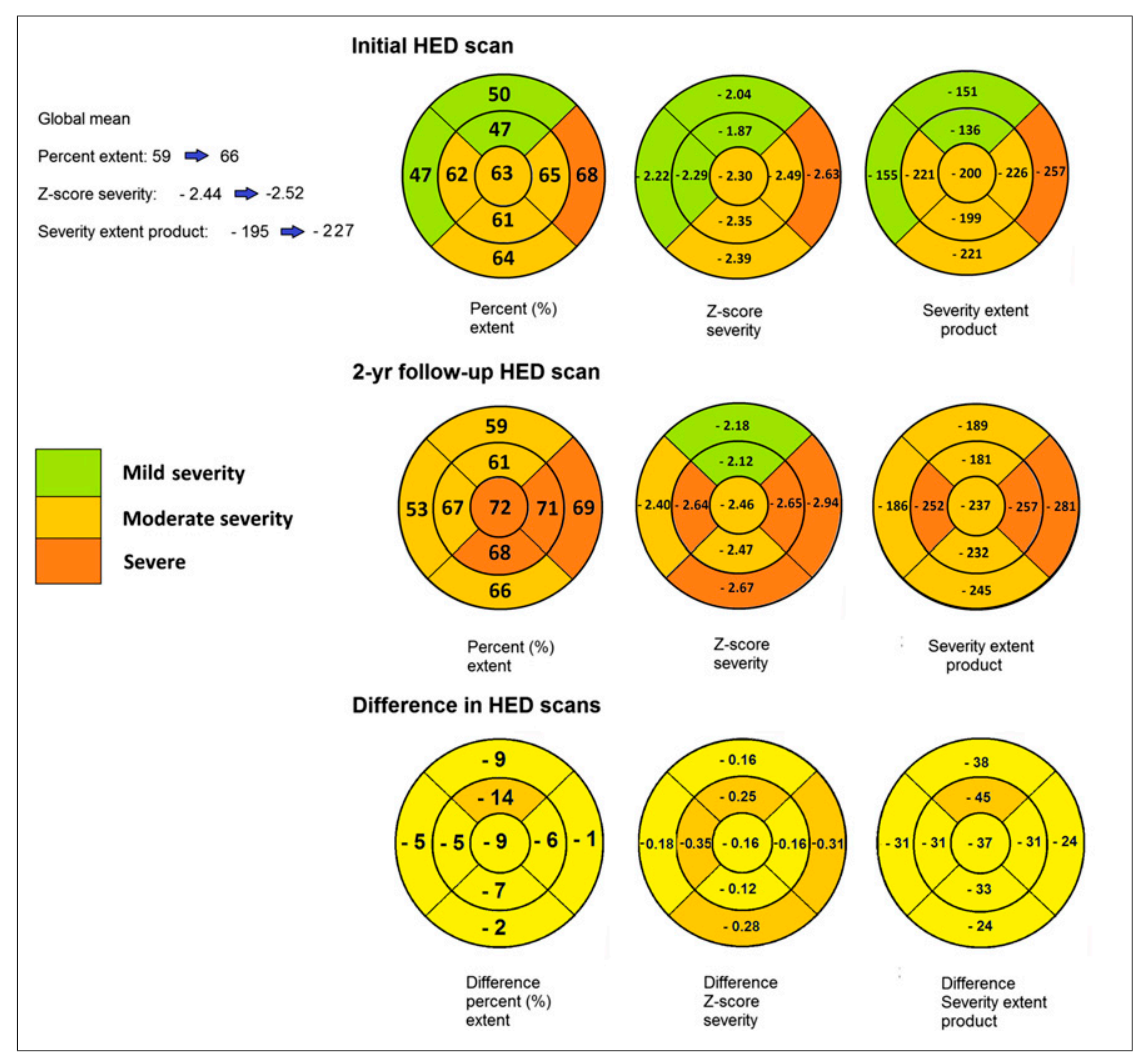

FIGURE 1. Bullseye plots using 9-segment model summarizing segmental distribution of sympathetic denervation with respect to mean percentage extent, $z$ score severity, and SEP, in comparison to global mean measurements in 23 patients, comparing baseline measurements with 2-y follow-up. There is a decline in global LV RI per annum of $4.6 \%$ translating to increasing abnormalities of LV segmental extent, $z$ score severity, and SEP. Over $2 y$, changes in percentage LV abnormality (59\% increasing to $66 \%), z$ score severity $(-2.4$ down to -2.5$)$, and SEP $(-195$ down to -227) indicate worsening cardiac sympathetic innervation. There is a general proximalto-distal gradient, with basal segments being relatively spared compared with distal segments.

significant heterogeneity and a regional pattern of decline that was predicated in part on baseline ${ }^{11} \mathrm{C}$-HED PET results. Patients with mildly affected scans at baseline showed further decline preferentially in lateral and inferior segments. In contrast, patients with severely denervated baseline scans affecting principally the lateral and inferior segments showed further progression preferentially in the anterior and septal segments, all of which appears to represent a pattern of catch-up eventually leading to global LV denervation.

In subjects with severely abnormal baseline ${ }^{11} \mathrm{C}-\mathrm{HED}$ PET scans, we have previously attributed this regional pattern to the hypothesis of redundancy of the cardiac sympathetic innervation of the anterior and septal LV walls in contrast to the more vulnerable innervation of the lateral and inferior walls by the left cardiac nerve, which runs with the left circumflex artery and is supplied only by the ipsilateral left-sided cervical sympathetic ganglia $(24,25)$. As the disease progresses, the redundancy of the anterior and septal LV innervation may no longer prevent decline in ${ }^{11} \mathrm{C}-\mathrm{HED}$ uptake, resulting in less pronounced regional heterogeneity on the 2-y follow-up PET scans.

In our current study, we found a binomial distribution, with one group of patients showing normal or mildly abnormal ${ }^{11} \mathrm{C}-\mathrm{HED}$ scans and the second group with severely denervated scans. In the first group, those with normal baseline scans showed no denervation after $2 \mathrm{y}$ of serial PET imaging, supporting the notion of a protected phenotype. In a relevant study, Tsujikawa et al. performed a chronologic study of ${ }^{123}$ I-MIBG scans in 70 IPD patients over a mean interval of 3 y (26). Although follow-up studies showed a significant decline in both the early and the delayed heart-to-mediastinal ratios, cluster analysis identified 2 groups of patients at baseline, those with markedly reduced ${ }^{123}$ I-MIBG $(n=42)$ and those with normal or mildly abnormal scans $(n=28)$. This second group with IPD with normal or mildly low ${ }^{123}$ I-MIBG uptake at the early stages of illness was characterized as femaledominant, young onset, slow progression in motor dysfunctions, and preserved cognitive function. Our imaging findings are similar to those mentioned above, although we did not observe the same clinical correlations, likely related to our small numbers.

A limitation of our study was the lack of a formal reproducibility analysis of ${ }^{11} \mathrm{C}$-HED PET without a threshold for least-significant change, which made it difficult to determine the significance of small changes in the mean ${ }^{11} \mathrm{C}-\mathrm{HED}$ RI within segments. This was pertinent for the subgroup with normal baseline of ${ }^{11} \mathrm{C}$-HED PET, as changes in individual ${ }^{11} \mathrm{C}$-HED RIs were considered within the range of test-retest reproducibility of the PET instrument. Determining the precision of ${ }^{11} \mathrm{C}-\mathrm{HED}$ PET is an area of future study. Additionally, our study is limited principally by the small number of IPD patients, particularly the group with serial ${ }^{11} \mathrm{C}$-HED PET. This may have limited the power to detect correlations to clinical manifestations. Having a larger number of IPD patients may also have given us an opportunity to explore further the finding of a protected phenotype, in which the cardiac sympathetic innervation may be spared in IPD. Also, a larger group may have given us a chance to follow a larger

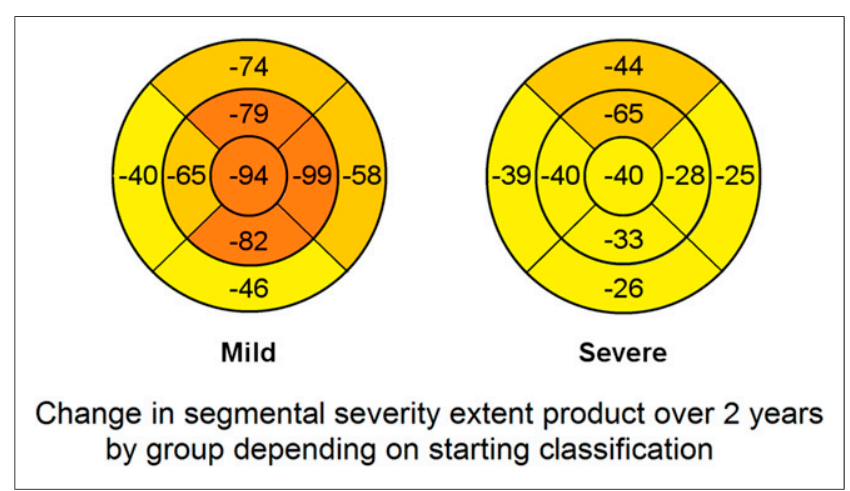

FIGURE 2. Bullseye plots summarizing decline in sympathetic denervation with respect to SEP, in 23 patients, comparing differences in baseline measurements with 2-y follow-up of SEP, based on starting category at baseline, either mild abnormality or severe. In patients with severe denervation at baseline preferentially affecting lateral wall, anterior and septal walls showed relatively greater decline, whereas patients with mild abnormality on PET scans at baseline had relatively greater progression in lateral, inferior, and apical walls. Patients with normal baseline ${ }^{11} \mathrm{C}-\mathrm{HED}$ PET had small changes that were not considered significant within margin of test-retest error for ${ }^{11} \mathrm{C}-\mathrm{HED}$ PET. Formal reproducibility analysis of ${ }^{11} \mathrm{C}-\mathrm{HED}$ is an area of future research. 


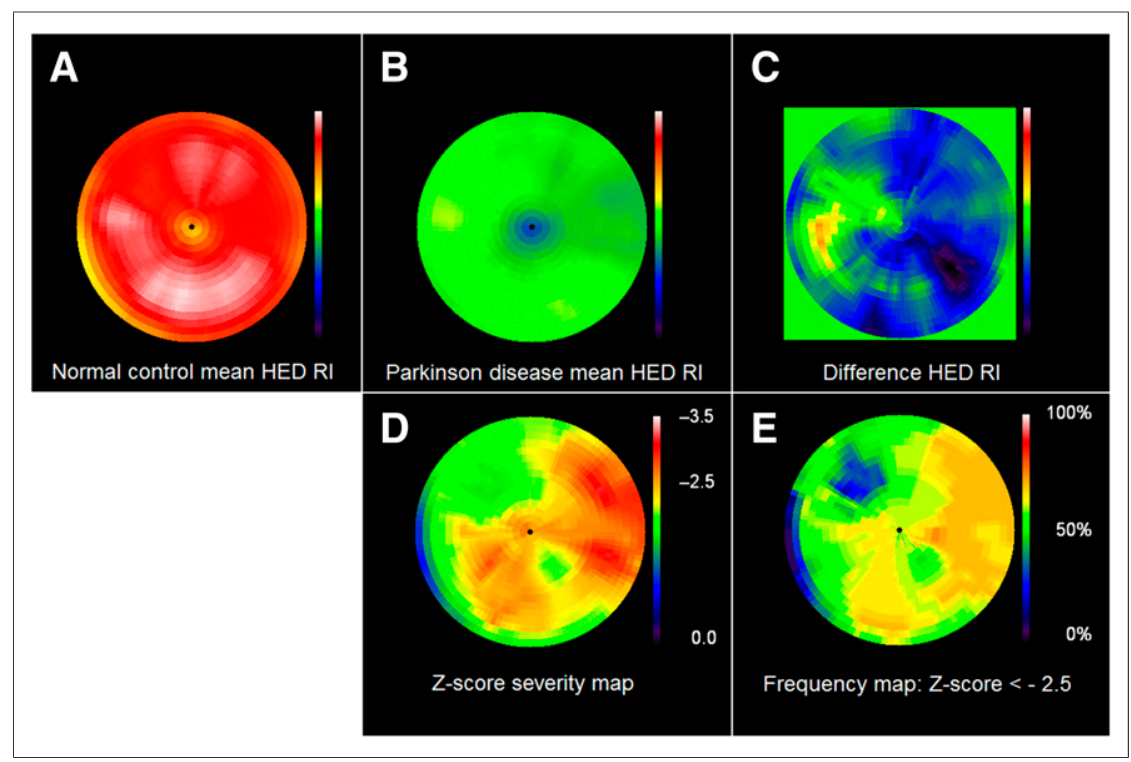

FIGURE 3. Comparison polar maps of normal control patients' $(n=33)$ mean ${ }^{11} \mathrm{C}-\mathrm{HED}$ RIs (A) and baseline IPD patients' $(n=23)$ mean ${ }^{11} \mathrm{C}$-HED RIs (B), demonstrating severe, global cardiac sympathetic denervation. (C) Mean difference in RI between baseline studies and 2-y follow-up studies demonstrating preferentially decline in anteroseptal and septal walls. (D) Segmental $z$ score severity polar map, generated by sector-to-sector comparison of IPD and normal control ${ }^{11} \mathrm{C}-\mathrm{HED} \mathrm{RI}$, representing characteristic regional pattern of sympathetic denervation in IPD. Proximal lateral wall is most severely affected, with relative sparing of anterior and proximal septal walls. (E) There is concordance in segmental distribution on both $z$ score severity polar map and frequency polar map representing percentage of IPD patients (i.e., $\mathrm{n} / 23 \times 100$ ) with abnormal sector $z$ score $\leq 2.5$ displayed on color scale ranging from $0 \%$ to $100 \%$.

\section{CONCLUSION}

Cardiac sympathetic denervation in IPD has a binomial distribution pattern, with a progressive decline in cardiac sympathetic neural integrity occurring at a modest rate over 2 y on ${ }^{11} \mathrm{C}$-HED scans with significant heterogeneity and regional pattern of involvement and decline.

\section{DISCLOSURE}

This study was supported by NIH NS015655 and P50 NS091856. Kirk A. Frey has research support from the NIH, GE Healthcare, and AVID Radiopharmaceuticals (Eli Lilly subsidiary). He also serves as a consultant to AVID Radiopharmaceuticals, MIMVista, Inc., Bayer-Schering, and GE Healthcare and holds equity (common stock) in GE Healthcare, Bristol-Myers, Merck, and Novo-Nordisk. No other potential conflict of interest relevant to this article was reported.

\section{ACKNOWLEDGMENTS}

We thank the patients, Christine Minderovic, Arijit Bhaumik, PET technologists, cyclotron operators, and chemists for assistance.

cohort of patients for a longer interval than $2 \mathrm{y}$ to determine with greater accuracy the outcome of the denervation process. We still do not have an accurate portrayal of the natural history of the denervation process, although we have clarified the marked heterogeneity of it.

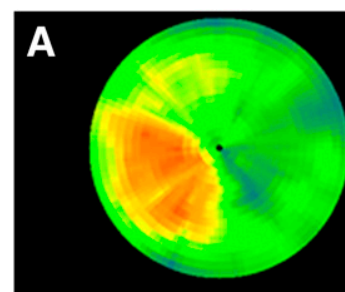

Baseline RI

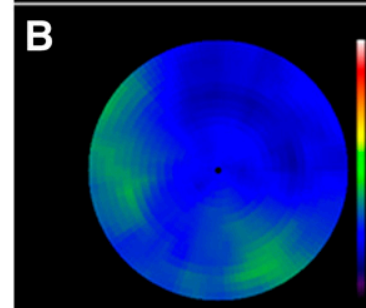

Baseline RI

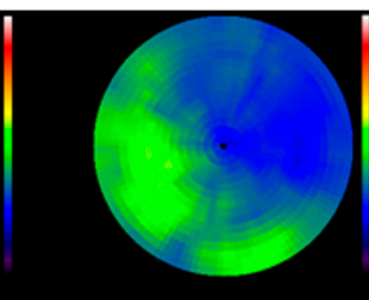

2 y follow-up RI

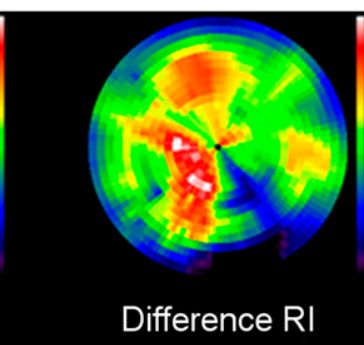

Difference RI

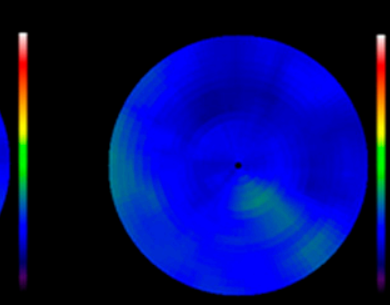

2 y follow-up RI

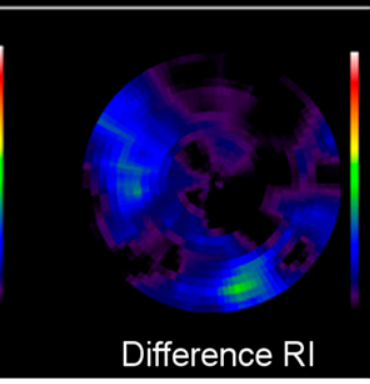

FIGURE 4. Examples of ${ }^{11} \mathrm{C}$-HED decline in IPD patients showing baseline ${ }^{11} \mathrm{C}-\mathrm{HED}$ RI (left), 2-y follow-up ${ }^{11} \mathrm{C}$-HED RI (middle), and difference ${ }^{11} \mathrm{C}$-HED RI (right) polar maps. (A) Partial ${ }^{11} \mathrm{C}-\mathrm{HED}$ denervation at baseline ${ }^{11} \mathrm{C}$-HED scan, with decline in ${ }^{11} \mathrm{C}-\mathrm{HED}$ uptake at $2 \mathrm{y}$, after initial sparing of anterior and septal walls. (B) Severe ${ }^{11} \mathrm{C}-\mathrm{HED}$ denervation at baseline, with mild further decline at $2 \mathrm{y}$, in septum and inferior LV walls.

\section{REFERENCES} $\alpha$-synuclein and mitochondrial bioenergetics regulate tetrahydrobiopterin levels in a human dopaminergic model of Parkinson disease. Free Radic Biol Med. 2014;67:58-68.

2. Jellinger KA. Synuclein deposition and non-motor symptoms in Parkinson disease. J Neurol Sci. 2011;310:107-111.

3. Akincioglu C, Unlu M, Tunc T. Cardiac innervation and clinical correlates in idiopathic Parkinson's disease. Nucl Med Commun. 2003;24:267-271.

4. Hamada K, Hirayama M, Watanabe H, et al. Onset age and severity of motor impairment are associated with reduction of myocardial ${ }^{123}$ I-MIBG uptake in Parkinson's disease. J Neurol Neurosurg Psychiatry. 2003;74:423-426.

5. Kim JS, Lee KS, Song IU, et al. Cardiac sympathetic denervation is correlated with Parkinsonian midline motor symptoms. J Neurol Sci. 2008;270:122-126.

6. Saiki S, Hirose G, Sakai K, et al. Cardiac ${ }^{123}$ I-MIBG scintigraphy can assess the disease severity and phenotype of PD. J Neurol Sci. 2004;220:105-111.

7. Spiegel J. Diagnostic and pathophysiological impact of myocardial MIBG scintigraphy in Parkinson's disease. Parkinsons Dis. 2010;2010:295346.

8. Taki J, Nakajima K, Hwang EH, et al. Peripheral sympathetic dysfunction in patients with Parkinson's disease without autonomic failure is heart selective and disease specific. Eur J Nucl Med. 2000;27:566-573.

9. Berding G, Schrader CH, Peschel T, et al. [N-methyl $\left.{ }^{11} \mathrm{C}\right]$ meta-hydroxyephedrine positron emission tomography in Parkinson's disease and multiple system atrophy. Eur J Nucl Med Mol Imaging. 2003;30:127-131.

10. Raffel DM, Koeppe RA, Little R, et al. PET measurement of cardiac and nigrostriatal denervation in parkinsonian syndromes. J Nucl Med. 2006; 47:1769-1777. 
11. Wong KK, Raffel DM, Koeppe RA, Frey KA, Bohnen NI, Gilman S. Pattern of cardiac sympathetic denervation in idiopathic Parkinson disease studied with ${ }^{11} \mathrm{C}$ hydroxyephedrine PET. Radiology. 2012;265:240-247.

12. Li ST, Dendi R, Holmes C, Goldstein DS. Progressive loss of cardiac sympathetic innervation in Parkinson's disease. Ann Neurol. 2002;52:220-223.

13. Goldstein DS, Holmes CS, Dendi R, Bruce SR, Li ST. Orthostatic hypotension from sympathetic denervation in Parkinson's disease. Neurology. 2002;58:1247-1255.

14. Berardelli A, Wenning GK, Antonini A, et al. EFNS/MDS-ES/ENS [corrected] recommendations for the diagnosis of Parkinson's disease. Eur J Neurol. 2013;20:16-34.

15. Orimo S, Amino T, Itoh $\mathrm{Y}$, et al. Cardiac sympathetic denervation precedes neuronal loss in the sympathetic ganglia in Lewy body disease. Acta Neuropathol (Berl). 2005;109:583-588.

16. Sakakibara R, Tateno F, Kishi M, Tsuyusaki Y, Terada H, Inaoka T. MIBG myocardial scintigraphy in pre-motor Parkinson's disease: a review. Parkinsonism Relat Disord. 2014;20:267-273.

17. Bengel FM, Schwaiger M. Assessment of cardiac sympathetic neuronal function using PET imaging. J Nucl Cardiol. 2004;11:603-616.

18. Langer O, Halldin C. PET and SPET tracers for mapping the cardiac nervous system. Eur J Nucl Med Mol Imaging. 2002;29:416-434.
19. Münch G, Ziegler S, Nguyen N, Hartmann F, Watzlowik P, Schwaiger M. Scintigraphic evaluation of cardiac autonomic innervation. J Nucl Cardiol. 1996;3:265-277.

20. Gelb DJ, Oliver E, Gilman S. Diagnostic criteria for Parkinson disease. Arch Neurol. 1999;56:33-39.

21. Bohnen NI, Albin RL, Koeppe RA, et al. Positron emission tomography of monoaminergic vesicular binding in aging and Parkinson disease. J Cereb Blood Flow Metab. 2006;26:1198-1212.

22. Goldstein DS, Holmes C, Li ST, Bruce S, Metman LV, Cannon RO III. Cardiac sympathetic denervation in Parkinson disease. Ann Intern Med. 2000;133:338-347.

23. Becker G, Muller A, Braune S, et al. Early diagnosis of Parkinson's disease. J Neurol. 2002;249(suppl 3):III/40-48.

24. Janes RD, Brandys JC, Hopkins DA, Johnstone DE, Murphy DA, Armour JA. Anatomy of human extrinsic cardiac nerves and ganglia. Am J Cardiol. 1986;57: 299-309.

25. Janes RD, Johnstone DE, Brandys JC, Armour JA. Functional and anatomical variability of canine cardiac sympathetic efferent pathways: implications for regional denervation of the left ventricle. Can J Physiol Pharmacol. 1986;64:958-969.

26. Tsujikawa K, Hasegawa Y, Yokoi S, et al. Chronological changes of ${ }^{123}$ I-MIBG myocardial scintigraphy and clinical features of Parkinson's disease. J Neurol Neurosurg Psychiatry. 2015;86:945-951. 